\title{
A infra-estrutura de transporte frente à expansão da cultura da soja no Brasil
}

\section{The transport infrastructure go-ahead the expansion of soybean cultivation in Brazil}

Tiago Santos Telles ${ }^{1}$; Maria de Fátima Guimarães ${ }^{2 *}$; Antônio Carlos Roessing ${ }^{3}$

\section{Resumo}

A soja se configura como a principal cultura do setor agrícola brasileiro, tanto pela área que ocupa como pelo impacto no Produto Interno Bruto do país. As vantagens tecnológicas comparativas na produção desta commodity colocam o Brasil como segundo maior produtor e abastecedor mundial. Entretanto, as limitações da infra-estrutura logística para o escoamento da produção elevam os custos de transporte. Assim, o estudo foi desenvolvido, a partir de um resgate histórico-econômico do cultivo da soja e da infra-estrutura de transporte, no período de 1975 a 2005, com base em metodologia descritiva, com o objetivo de verificar as restrições logísticas no transporte da oleaginosa. De modo geral, enquanto o crescimento da área cultivada com soja foi de $305 \%$, no período analisado, o da infra-estrutura de transportes foi de apenas $25,3 \%$. O estudo revela que a expansão da área ocupada pela cultura da soja, decorrente de avanços tecnológicos, não foi acompanhada pelo desenvolvimento da infra-estrutura de transporte, prejudicando sua competitividade.

Palavras-chave: Agricultura, economia, logística, desenvolvimento, competitividade

\begin{abstract}
The soybean is the main crop of the Brazilian agricultural sector, both for the area it occupies as by the impact on the gross domestic product of the country. The comparative technological advantages in the production of this commodity put Brazil as the second largest producer and supplier of the world. However, the limitations of the logistics infrastructure for the disposal of production raise the costs of transport. The paper was developed from a historical and economic recovery soybean cultivation and the transport infrastructure, in the period from 1975 to 2005, based on descriptive methodology. Overall, while growth of soybean area cultivated was $305 \%$ in the period analyzed, the transport infrastructure was only $25.3 \%$. This study shows that the expansion of the occupied area by the soybean crop, due to technological advances, was not accompanied by the development of transport infrastructure, undermining their competitiveness.
\end{abstract}

Key words: Agriculture, economy, logistics, development, competitiveness

1 Universidade Estadual de Londrina - UEL. Departamento de Agronomia. Londrina, PR. Bolsista da CAPES.

2 UEL. Departamento de Agronomia. Londrina, PR. Bolsista de Produtividade em Pesquisa do CNPq. E-mail: mfatima@uel.br

3 Empresa Brasileira de Pesquisa Agropecuária. Embrapa Soja. Londrina, PR.

* Autor para correspondência. 


\section{Introdução}

A soja foi introduzida no Brasil pelos imigrantes japoneses em 1908 e disseminada oficialmente no Rio Grande do Sul em 1914. Sua expansão se efetivou nos anos 70, com o interesse crescente da indústria de óleo e a demanda do mercado internacional (CÂMARA, 1996). Até 1975, toda a produção brasileira era realizada com cultivares e técnicas importadas dos Estados Unidos e se concentrava nos estados do Sul, onde as variedades americanas encontravam condições semelhantes às de seu país de origem.

Trabalhos da área de melhoramento genético da Empresa Brasileira de Pesquisa Agropecuária (EMBRAPA) resultaram em cultivares chamadas de "período juvenil longo", no qual a planta desenvolvia a capacidade de retardar o florescimento quando cultivada em regiões tropicais, o que permitiu a criação, dentre outras, da cultivar Tropical, possibilitando a produção comercial da soja nas regiões centro-oeste, norte e nordeste, com o aproveitamento econômico das terras de cerrados do centro-oeste e de áreas com pastagens degradadas.

No Brasil, a soja se constituiu numa das mais importantes commodities, movimentando grande montante de recursos e divisas no complexo agroindustrial. $\mathrm{Na}$ safra 2005/06 ocupou $47,1 \%$ da área plantada com grãos no país, atingindo uma produção de 55,414 milhões de toneladas (COMPANHIA NACIONAL DE ABASTECIMENTO, 2007). Além disso, o país colaborou com $25 \%$ da produção mundial de soja, de aproximadamente 218 milhões de toneladas, ficando atrás apenas dos EUA, que deteve $38 \%$ (UNITED STATES DEPARTMENT OF AGRICULTURE, 2007). O volume mundial comercializado em 2006 ficou em torno de 63 milhões de toneladas e o Brasil respondeu por aproximadamente $30 \%$ do total exportado (FOOD AND AGRICULTURE ORGANIZATION OF THE UNITED NATIONS, 2006).
O Produto Interno Bruto (PIB) do agronegócio brasileiro atingiu, em 2006, a cifra de $\mathrm{R} \$ 540,06$ bilhões; o da agropecuária foi de R \$ 149,80 bilhões, sendo que o da agricultura somou R \$ 84,97 bilhões. O Valor Bruto da Produção (VBP) da soja fechou 2006 em R\$ 22,98 bilhões (CONFEDERAÇÃO NACIONAL DA AGRICULTURA E PECUÁRIA, 2006).

Essa história de sucesso, porém, de acordo com Reid e Souza Junior (2005), Hesse e Rodrigue (2004), Castro (2003), Toyoshima e Ferreira (2002) e Martins (2001), apresenta sérias dificuldades em relação à infra-estrutura de transportes para o escoamento da produção da leguminosa no Brasil, que aumentam custos e provocam perdas de divisas e competitividade do produto.

Nesse sentido, o objetivo deste trabalho foi analisar, a partir de um resgate histórico-econômico, a infra-estrutura disponível para o escoamento da produção de soja, indicando sua evolução. Para tanto, foram estudados os principais modais do sistema de transporte no Brasil, para uma série que compreende um período de trinta anos, tomando como referência os anos de 1975, 1985, 1995 e 2005.

\section{Material e métodos}

Nessa pesquisa, baseada em apreciações ex post $\mathrm{fact}^{4}$, as evidências giram em torno de uma dinâmica nacional que, por meio de recortes dimensionais, estrutura-se na economia rural para a compreensão dos processos de territorialização e territorialidade da produção e da infra-estrutura logística de transporte.

Para tanto, foram consultadas fontes de dados da Companhia Nacional de Abastecimento - CONAB (2006) e do Instituto Brasileiro de Geografia e Estatística - IBGE (1970, 1977, 1987, 1997a,

\footnotetext{
4 Investigação sistemática e empírica na qual o pesquisador não tem controle direto sobre as variáveis, uma vez que já ocorreram. Neste caso são feitas inferências sobre as relações entre as variáveis em observação (GIL, 2002).
} 
1997b, 2006b, 2007a, 2007b), a fim de se obter informações detalhadas, com cobertura temporal, para o desenvolvimento das análises.

As estatísticas relativas à atividade de transportes mensuram a evolução e as principais características em termos econômicos e operacionais de suas distintas modalidades: rodoviário, ferroviário e hidroviário.

As fontes das informações estatísticas sobre o transporte rodoviário foram as da Agência Nacional de Transportes Terrestres - ANTT (2006) e do IBGE (1977, 1987, 1997a, 2007a), apresentando a extensão da rede rodoviária nacional, englobando as rodovias federais, estaduais e municipais por unidade da federação. Para o ano de 2005, foi apresentada a malha rodoviária brasileira pavimentada e não-pavimentada. As mesmas fontes foram utilizadas para as estatísticas ferroviárias, e forneceram os dados sobre a extensão da rede de ferrovias por estado. No que se refere ao transporte hidroviário, foram consultados a Agência Nacional de Transportes Aquaviários - ANTAQ (2006) e o IBGE (1977, 1987, 1997a, 2007a), para obter o número de portos existentes no país.

Para a produção de soja no Brasil nos anos de 1975, 1985 e 2005, os dados foram tabulados a partir das versões impressas da Pesquisa Agrícola Municipal (PAM) do IBGE (1997b, 2006b); e para o ano de 1995 as informações foram compiladas a partir da base de dados on-line do IBGE (2007b). Em relação a infra-estrutura de transporte, os valores foram retirados das versões impressas do Anuário Estatístico do Brasil de 1976, 1986, 1996 e 2006.

\section{Resultados e discussão}

A história da produção de soja no Brasil é intensa. Em pouco mais de três décadas esta deixou de ser uma cultura marginal e se tornou um dos principais produtos brasileiros de exportação. $\mathrm{Na}$ safra 2005/2006, 17 dos 26 estados brasileiros, além do Distrito Federal, apresentavam áreas plantadas com a leguminosa (CONAB, 2006). Dados absolutos e relativos demonstraram a marcante performance da produção da soja no Brasil, sendo que nenhuma outra commodity conseguiu expansão semelhante.

A lavoura da soja começou a expandir-se mais vigorosamenteno Brasilnos anos 70, principalmente nos estados do sul. Cultivada no Rio Grande do Sul, como uma opção de rotatividade com o trigo, expandiu-se para os estados de Santa Catarina, do Paraná e de São Paulo (CÂMARA, 1996). Nesse período, esses estados foram responsáveis por $85,3 \%$ da área total plantada com a leguminosa (1,3 milhão de hectares) e por $85,5 \%$ da produção total (cerca de 1,28 milhão de toneladas). As demais regiões do país somavam apenas $14,7 \%$ da área produzida (IBGE, 1970).

Em 1975, 19 estados brasileiros e o Distrito Federal produziam soja, cultivada em 1020 municípios, em uma área de 5,6 milhões de hectares. Na Região Sul, 451 municípios ocupavam 89,7\% dessa área. Na Região Sudeste, 504 municípios ocupavam $7 \%$ da área. Já na Região Centro-Oeste, 55 municípios tomavam 3,3\% da área. A Região Nordeste apresentava 8 municípios para 465 hectares, e a Região Norte, 2 municípios para 283 hectares (Tabela 1).

Ao longo da década de 1980 a soja continuava a predominar nos estados meridionais, mas teve crescimento expressivo nas novas fronteiras agrícolas, atingindo uma produção de 15,1 milhões de toneladas. Em 1980, os quatro estados pioneiros na produção de soja no Brasil responderam por cerca de $58 \%$ da área total cultivada (11,6 milhões de hectares), uma participação ainda expressiva, mas menor que os 85,3\% registrados em 1970 (IBGE, 1997b), ocorrendo um significativo aumento na área plantada e na produção do centro-oeste. 
Tabela 1. Produção de soja no Brasil, 1975, 1985, 1995 e 2005.

\begin{tabular}{|c|c|c|c|c|c|c|c|c|}
\hline \multirow{3}{*}{$\mathbf{U F}$} & \multicolumn{8}{|c|}{ ANOS DE REFERÊNCIA } \\
\hline & \multicolumn{2}{|c|}{1975} & \multicolumn{2}{|c|}{1985} & \multicolumn{2}{|c|}{1995} & \multicolumn{2}{|c|}{2005} \\
\hline & (a) & (b) & (a) & (b) & (a) & (b) & (a) & (b) \\
\hline $\mathrm{RO}$ & 1 & 282 & 1 & 1.240 & 1 & 4.500 & 10 & 75.275 \\
\hline $\mathrm{AC}$ & 0 & 0 & 1 & 1 & 0 & 0 & 2 & 55 \\
\hline $\mathrm{AM}$ & 0 & 0 & 1 & 13 & 0 & 0 & 3 & 2.206 \\
\hline RR & 0 & 0 & 15 & 45 & 0 & 0 & 5 & 13.000 \\
\hline PA & 1 & 1 & 2 & 397 & 0 & 0 & 20 & 68.410 \\
\hline $\mathrm{AP}$ & 0 & 0 & 0 & 0 & 0 & 0 & 0 & 0 \\
\hline TO & 0 & 0 & 60 & 27.140 & 22 & 20.117 & 77 & 355.300 \\
\hline MA & 1 & 68 & 126 & 7.169 & 13 & 87.690 & 32 & 372.074 \\
\hline PI & 1 & 34 & 2 & 221 & 7 & 12.784 & 15 & 198.547 \\
\hline $\mathrm{CE}$ & 1 & 81 & 1 & 50 & 0 & 0 & 1 & 210 \\
\hline $\mathrm{RN}$ & 0 & 0 & 0 & 0 & 0 & 0 & 0 & 0 \\
\hline $\mathrm{PB}$ & 1 & 2 & 1 & 169 & 0 & 0 & 0 & 0 \\
\hline PE & 2 & 59 & 4 & 457 & 1 & 36 & 0 & 0 \\
\hline $\mathrm{AL}$ & 1 & 1 & 3 & 279 & 0 & 0 & 3 & 330 \\
\hline SE & 0 & 0 & 1 & 24 & 0 & 0 & 0 & 0 \\
\hline BA & 1 & 220 & 3 & 51.832 & 8 & 470.575 & 12 & 870.000 \\
\hline MG & 222 & 48.359 & 386 & 362.730 & 100 & 600.655 & 158 & 1.118 .867 \\
\hline ES & 2 & 110 & 2 & 275 & 0 & 0 & 0 & 0 \\
\hline RJ & 1 & 42 & 1 & 40 & 0 & 0 & 0 & 0 \\
\hline SP & 279 & 348.774 & 308 & 470.057 & 215 & 530.000 & 347 & 781.210 \\
\hline PR & 168 & 1.615 .302 & 216 & 2.079 .973 & 279 & 2.206 .249 & 377 & 4.154 .667 \\
\hline $\mathrm{SC}$ & 93 & 263.876 & 141 & 403.530 & 111 & 204.008 & 152 & 350.692 \\
\hline $\mathrm{RS}$ & 190 & 3.195 .977 & 214 & 3.611 .032 & 340 & 3.006 .535 & 390 & 3.733 .822 \\
\hline MS & 31 & 121.829 & 59 & 958.568 & 67 & 1.043 .689 & 67 & 2.025 .155 \\
\hline MT & 1 & 3 & 56 & 822.821 & 55 & 2.322 .825 & 111 & 6.106 .654 \\
\hline GO & 22 & 61.905 & 85 & 599.555 & 109 & 1.121 .511 & 172 & 2.663 .380 \\
\hline DF & 1 & 3 & 1 & 37.055 & 1 & 43.831 & 1 & 59.020 \\
\hline TOTAL & 1020 & 5.656 .928 & 1690 & 9.434 .686 & 1329 & 11.675 .005 & 1955 & 22.948 .874 \\
\hline
\end{tabular}

Fonte: Elaborada a partir dos dados da Produção Agrícola Municipal (PAM) - IBGE dos anos de 1975, 1985,1995 e 2005.

(a) Número de municípios que cultivaram soja.

(b) Área cultivada de soja em hectares.

No ano de 1985, 24 estados e o Distrito Federal, representados por 1690 municípios, cultivavam soja no Brasil, em uma área de aproximadamente 9,4 milhões de hectares, com uma taxa de crescimento, em relação ao ano de 1975 , de $65,69 \%$ no número de municípios e de $65,17 \%$ na área de produção. Nesse ano, a Região Sul se manteve como maior produtora, mas a Região Centro-Oeste assumiu a segunda posição, passando a ocupar $25,6 \%$ da área produzida. O estado do Mato Grosso do Sul se destacava, tornando-se o terceiro maior produtor (Tabela 1).
Em 1990, Mato Grosso do Sul foi o quarto produtor de soja do país (com 1,3 milhão de hectares plantados). Nesseano, a lavoura já ganhava expressão em quase todo o estado, com exceção da Região do Pantanal. No estado de Goiás, o quinto estado produtor (com cerca de um milhão de hectares), a soja também ocupava áreas ao leste. Além disso, observava-se a expansão e consolidação da lavoura no Triângulo Mineiro e no oeste central de Minas Gerais. O mesmo acontecia no oeste da Bahia que, em 1975, nem aparecia como região produtora. O Rio Grande do Sul e o Paraná permaneciam como 
os principais estados produtores, concentrando mais de $80 \%$ das terras plantadas com soja no país (IBGE, 1997b).

Em 1995, 15 estados brasileiros produziam soja, em 1329 municípios, num espaço total de pouco mais de 11,67 milhões de hectares. A Região Sul detinha 46,4\% das terras cultivadas; a Região Centro-Oeste, 38,8\%; e as demais regiões do país, 14,8\%. Nesse período houve uma redução no número de estados dedicados a essa cultura. $\mathrm{O}$ ano de 1995 apresentou um crescimento de 106,4\% na área de produção e de 30,3\% no número de municípios, comparado a 1975. Em relação a 1985 , houve um crescimento de $23,7 \%$ para a área e um decréscimo de $21,36 \%$ no número de municípios (Tabela 1).

Em 2005, 19 estados e o Distrito Federal produziram soja em 1955 municípios, numa extensão de $22.948,874$ hectares. O crescimento em relação a 1975 foi de $305 \%$ quanto à área, e de $91,67 \%$ em relação ao número de municípios; no ano de 1985 o crescimento foi de $143,2 \%$ para a área e $15,7 \%$ para os municípios; e em 1995, a taxa de crescimento da área foi de $96,6 \%$, enquanto a dos municípios foi de $47,1 \%$ (Tabela 1$)$.
No ano de 2005, os estados meridionais responderam por $35,9 \%$ da área cultivada com a oleaginosa. Os $64,1 \%$ restantes (pouco mais de 14,7 milhões de hectares) se localizavam predominantemente nos cerrados. Neste ano, Mato Grosso assumiu o status de maior produtor, com mais de 6 milhões de hectares, seguido pelo Paraná (com mais 4 milhões de hectares) e pelo Rio Grande do Sul (pouco mais de 3,7 milhões hectares). E da quarta à sétima posições estavam estados com extensas áreas de cerrados, respectivamente, Mato Grosso do Sul, Goiás, Bahia e Minas Gerais (Tabela 1).

A produtividade média nacional, na safra 2005/2006, foi de $2.403 \mathrm{~kg} / \mathrm{ha}$ e a produção de soja foi de pouco mais de 53 milhões de toneladas. O estado do Pará apresentou a maior produtividade, $2.987 \mathrm{~kg} / \mathrm{ha}$, seguido por Roraima com $2.800 \mathrm{~kg} /$ ha, Distrito Federal com $2.699 \mathrm{~kg} / \mathrm{ha}$, Mato Grosso com $2.695 \mathrm{~kg} / \mathrm{ha}$ e Maranhão com $2.680 \mathrm{~kg} / \mathrm{ha}$. Em relação à produção o estado do Mato Grosso foi o grande destaque, produzindo mais de 15 milhões de toneladas, seguido pelos estados do Paraná $(9,389$ milhões), Rio Grande do Sul (7,518 milhões), Goiás (6,396 milhões) e Mato Grosso do Sul (4,375 milhões) (Tabela 2).

Tabela 2. Produtividade e produção de soja no Brasil, safra 2005/2006.

\begin{tabular}{lcc}
\hline UF & PRODUTIVIDADE ( kg/ha) & PRODUÇ̃̃ (mil toneladas) \\
\hline Bahia & 2.282 & $1.991,3$ \\
Distrito Federal & 2.699 & 145,7 \\
Goiás & 2.570 & $6.396,7$ \\
Maranhão & 2.680 & $1.025,1$ \\
Mato Grosso & 2.695 & $15.877,6$ \\
Mato Grosso do Sul & 2.280 & $4.375,5$ \\
Minas Gerais & 2.340 & $2.482,5$ \\
Pará & 2.987 & 238,1 \\
Paraná & 2.390 & $9.389,3$ \\
Piauí & 2.347 & 544,5 \\
Rio Grande do Sul & 1.935 & $7.518,6$ \\
Rondônia & 2.660 & 283,0 \\
Roraima & 2.800 & 56,0 \\
Santa Catarina & 2.400 & 814.8 \\
São Paulo & 2.390 & $1.569,3$ \\
Tocantins & 2.263 & 700,4 \\
Brasil & 2.403 & $53.413,9$ \\
\hline
\end{tabular}

Fonte: Elaborada a partir dos dados da CONAB, 2006. 
Dados do IBGE (1997b) mostram que, em 1980, o rendimento médio da soja no Rio Grande do Sul era de $1.438 \mathrm{~kg} / \mathrm{ha}$ e no Paraná era de $2.240 \mathrm{~kg} /$ ha. Para a safra de 2005/2006, a tabela 2 aponta, para os mesmos estados, $1.935 \mathrm{~kg} / \mathrm{ha}$ e $2.390 \mathrm{~kg} / \mathrm{ha}$, respectivamente, fato que demonstra o resultado das tecnologias aplicadas no setor. O desempenho do Centro-Oeste, que concentra boa parte da produção de soja, chama atenção: a média para a região na safra de 2005/06 é de $2.561 \mathrm{~kg} /$ ha, acima da média nacional (Tabela 2).

Os principais estados produtores são: Mato Grosso (15.877,6 milhões de toneladas, 29,7\% do
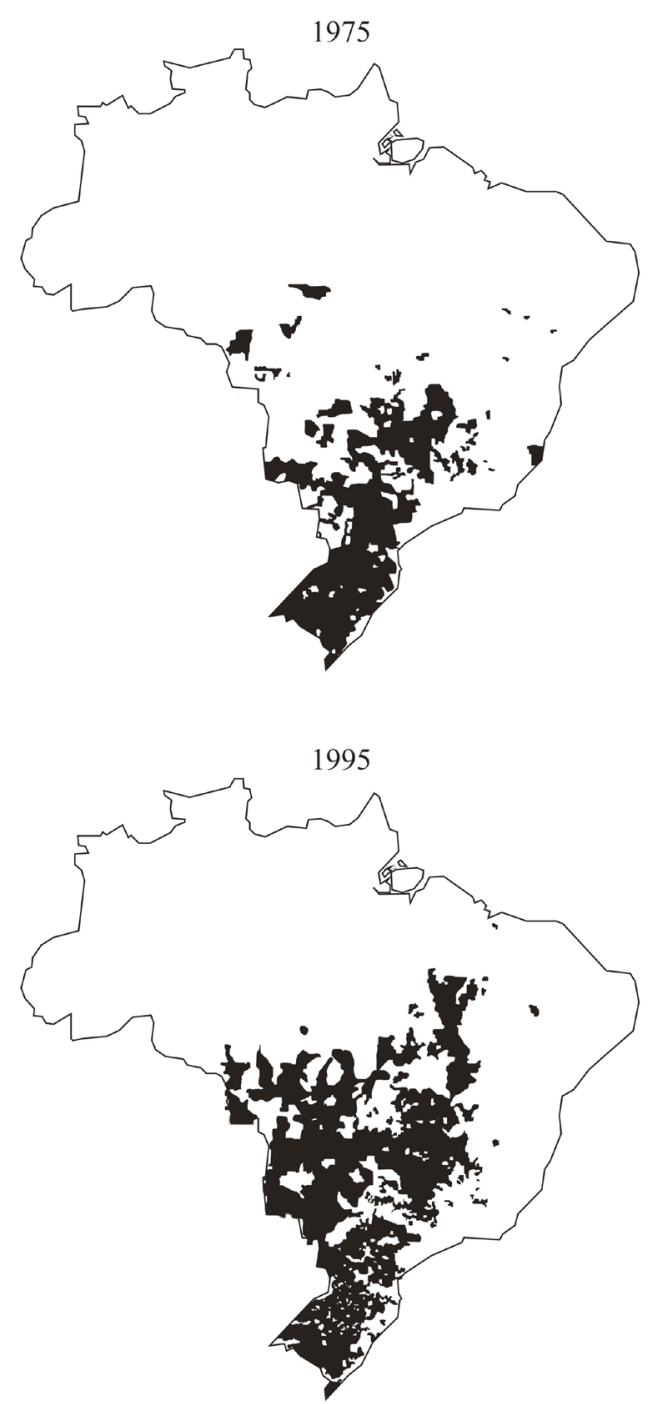

total), Paraná (9.389,3 milhões, $17,5 \%$ do total), Rio Grande do Sul (7.518,6 milhões de toneladas, $14,8 \%$ do total), Goiás (11,98\%), Mato Grosso do Sul (8,19\%) e Minas Gerais (4,65\%). A Região Centro-Oeste contribuiu com $50,17 \%$ da produção de soja do país, enquanto que o centro-sul contribuiu com 40,77\% (Tabela 2).

Quanto ao número de municípios que cultivaram soja, entre 1975 e 2005, nota-se que em 1975 havia 1020; em 1985, 1690; em 1995, 1329; e em 2005, 1955. Assim, pode-se observar que, ao longo desses trinta anos, os municípios produtores foram se expandindo por todo o território brasileiro (Figura 1).
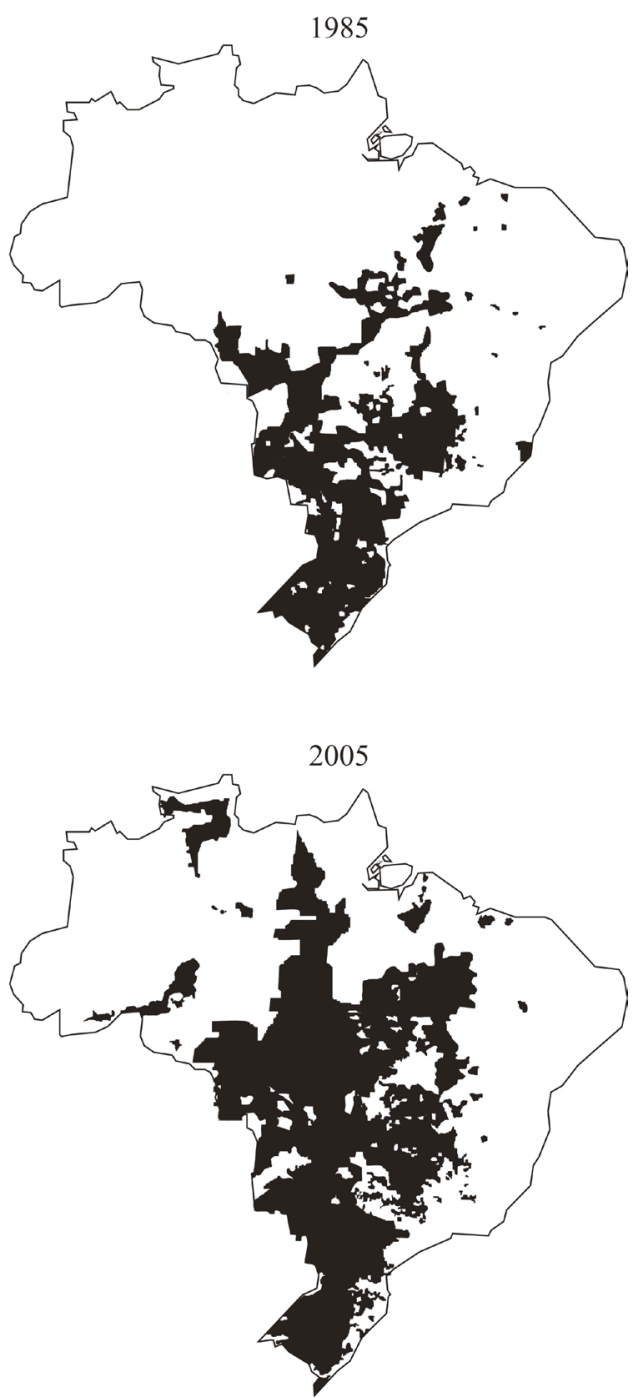

Figura 1. Municípios produtores de soja no Brasil, 1975, 1985, 1995 e 2005.

Fonte: Elaborada a partir dos dados da PAM/IBGE dos anos de 1975, 1985, 1995 e 2005. 
Este contexto mostra que a produção da soja no Brasil é moderna e eficiente. Sua competitividade está nas vantagens comparativas relacionadas ao clima (regime de chuvas e energia solar), à disponibilidade de água e de terras agricultáveis que permitem alta produtividade, além de tecnologia, principalmente relativa ao desenvolvimento de cultivares adaptadas a todo o território nacional. Contudo, os problemas de infra-estrutura e logística levam todo esse diferencial competitivo a ser desperdiçado.

De acordo com Samuels (2003), a estabilização da economia e a eliminação do processo inflacionário brasileiro recuperaram entre os agentes econômicos a noção de preços relativos, trazendo à tona ineficiências da infra-estrutura que reduzem a competitividade dos produtos brasileiros, uma vez que elevam consideravelmente os custos. E, custos de transporte elevados geram desestímulo ao setor.

Roehner (1996), Hesse e Rodrigue (2004), Short e Kopp (2005), Martins et al. (2005), Ojima (2006) mostram que um dos segmentos que interferem na eficiência dos diversos setores da economia de um país é o de transporte. Melhorias em seu sistema podem corresponder a um diferencial nos preços. No caso do complexo soja, esse estágio absorve cerca de 30\% dos gastos (SOARES; CAIXETA-FILHO, 1997). O Instituto Brasileiro de Economia (2005) relata que o produtor brasileiro de soja arca com um dispêndio médio de $25 \%$ de suas receitas com custos de transporte, enquanto o produtor norte-americano tem uma despesa média com transporte inferior a $10 \%$ da receita obtida.

A utilização de cada modal viário deve ser feita de acordo com a disponibilidade de infra-estrutura e levando-se em consideração as despesas como um todo, pois, além do frete, os gastos com transporte na exportação envolvem itens como demurrage de navios e detention de contêineres ${ }^{5}$, diárias de caminhões e de trens, todos associados a penalidades decorrentes por sobrestada e ociosidade desses ativos (ZARZOSO; BURGUET; MENÉNDEZ, 2003).

O transporte da soja nas diversas etapas pode ser realizado por diferentes modais de transporte: rodoviário, ferroviário e hidroviário. Essa distribuição se faz em decorrência de peculiaridades geográficas e regionais. Entretanto, conforme apontamentos de Castro (2002), a infra-estrutura de transporte disponível no Brasil é significativamente menor do que aquela existente em outros países de grandes extensões territoriais. Segundo o mesmo autor, para quem estiver na situação de tomador de preços, a tarefa de maior alcance é minimizar custos para ser competitivo. A separação entre produção agrícola e as regiões de consumo e exportação demanda um sistema de grande volume e baixo custo operacional, aspectos inerentes ao transporte ferroviário e hidroviário.

No ano de 1975, o país possuía uma malha rodoviária de aproximadamente 1,3 milhão de quilômetros; ferroviária, de pouco mais de 30 mil quilômetros; e dispunha de 25 portos. A Região Sudeste detinha $31,7 \%$ das rodovias, seguida pela Região Sul, 27,7\%, Nordeste, 26,2\%, Centro-Oeste, $12,2 \%$ e Norte, $2,5 \%$. A rede ferroviária concentrava $46,6 \%$ de sua extensão na Região Sudeste, 23,2\% na Sul, $23,3 \%$ na Nordeste, $6,2 \%$ na Centro-Oeste e $0,6 \%$ na Norte (Tabela 3 ).

Comparando-se os anos de 1975 e 1875, vêse que o modal rodoviário teve um crescimento de $10,93 \%$, atingindo mais de 1,4 milhão de quilômetros enquanto o ferroviário apresentou um decréscimo de $3,47 \%$. No entanto, houve um crescimento no número de portos, passando de 25 para 45, sendo que 6 foram implantados em locais onde antes não existia essa estrutura. Em 1985, as vias rodoviárias foram ampliadas em quase todos os estados brasileiros (Tabela 3).

\footnotetext{
5 Penalidades decorrentes por sobrestada e ociosidade desses ativos.
} 
Tabela 3. Infra-estrutura de transporte no Brasil, 1975, 1985, 1995 e 2005.

\begin{tabular}{|c|c|c|c|c|c|c|c|c|c|c|c|c|}
\hline \multirow{3}{*}{ UF } & \multicolumn{12}{|c|}{ ANOS DE REFERÊNCIA } \\
\hline & \multicolumn{2}{|c|}{1975} & \multicolumn{2}{|r|}{1985} & \multicolumn{2}{|c|}{1995} & \multicolumn{2}{|c|}{2005} & \multicolumn{2}{|r|}{1975} & \multicolumn{2}{|c|}{1985} \\
\hline & (a) & (b) & (c) & (a) & (b) & (c) & (a) & (b) & (c) & (a) & (b) & (c) \\
\hline RO & 2441,4 & 0 & 0 & 9723 & 0 & 1 & 22357 & 0 & 1 & 26633,4 & 0 & 1 \\
\hline $\mathrm{AC}$ & 1969 & 0 & 0 & 2232 & 0 & 0 & 2195 & 0 & 0 & 8052,2 & 0 & 0 \\
\hline $\mathrm{AM}$ & 7768,5 & 0 & 1 & 5521 & 0 & 1 & 6186 & 0 & 1 & 15055,8 & 0 & 1 \\
\hline $\mathrm{RR}$ & 1912,9 & 0 & 0 & 3202 & 0 & 0 & 4867 & 0 & 0 & 8023,9 & 0 & 0 \\
\hline PA & 16975,7 & 0 & 1 & 22501 & 329 & 3 & 34344 & 370 & 3 & 42291,0 & 370 & 3 \\
\hline AP & 1555,6 & 194 & 0 & 2146 & 194 & 1 & 2115 & 194 & 1 & 7264,2 & 194 & 1 \\
\hline TO & 0 & 0 & 0 & 0 & 0 & 0 & 25117 & 0 & 0 & 37768,5 & 0 & 0 \\
\hline MA & 43848,4 & 466 & 0 & 53881 & 1091 & 1 & 52854 & 1367 & 1 & 58286,9 & 1400 & 1 \\
\hline PI & 45830,1 & 554 & 0 & 50466 & 518 & 0 & 52737 & 277 & 0 & 60985,8 & 230 & 0 \\
\hline $\mathrm{CE}$ & 64713,3 & 1319 & 1 & 47561 & 1157 & 1 & 48210 & 1149 & 1 & 53388,9 & 1058 & 1 \\
\hline $\mathrm{RN}$ & 24587,5 & 472 & 1 & 26357 & 522 & 2 & 26945 & 556 & 2 & 27998,0 & 560 & 2 \\
\hline PB & 32093,1 & 692 & 1 & 32924 & 737 & 1 & 33205 & 716 & 1 & 35624,8 & 687 & 1 \\
\hline PE & 34838,9 & 1128 & 1 & 41300 & 1034 & 1 & 41340 & 1062 & 2 & 42950,5 & 1070 & 2 \\
\hline $\mathrm{AL}$ & 10128,7 & 385 & 1 & 13081 & 331 & 1 & 12989 & 393 & 1 & 14928,2 & 400 & 1 \\
\hline SE & 7771,1 & 270 & 1 & 8937 & 235 & 1 & 9510 & 286 & 1 & 5719,4 & 295 & 1 \\
\hline BA & 78123 & 1908 & 2 & 118684 & 1296 & 3 & 119544 & 1593 & 3 & 135741,1 & 1490 & 3 \\
\hline MG & 203557 & 6338 & 0 & 226661 & 5595 & 1 & 232390 & 5120 & 1 & 277467,3 & 4773 & 1 \\
\hline ES & 22998,6 & 429 & 1 & 29440 & 441 & 6 & 30056 & 522 & 6 & 31461,1 & 558 & 6 \\
\hline RJ & 22128,1 & 1690 & 3 & 23865 & 1580 & 5 & 22069 & 1506 & 5 & 25081,4 & 1473 & 5 \\
\hline SP & 160584,6 & 5935 & 2 & 194705 & 5929 & 4 & 195026 & 5924 & 4 & 200861,0 & 5930 & 3 \\
\hline PR & 127851,5 & 2236 & 2 & 142371 & 2240 & 2 & 260834 & 2243 & 2 & 124209,1 & 2245 & 3 \\
\hline $\mathrm{SC}$ & 78889,5 & 1279 & 4 & 88098 & 1318 & 3 & 61396 & 1370 & 3 & 106791,3 & 1424 & 3 \\
\hline $\mathrm{RS}$ & 153616,7 & 3638 & 3 & 100411 & 3375 & 5 & 138453 & 3359 & 5 & 157181,6 & 3460 & 5 \\
\hline MS & 0 & 0 & 0 & 48556 & 0 & 1 & 53844 & 1208 & 1 & 92991,3 & 1230 & 1 \\
\hline MT & 66395,8 & 1172 & 0 & 43672 & 1202 & 1 & 83651 & 0 & 1 & 57335,2 & 0 & 1 \\
\hline GO & 92539,1 & 675 & 0 & 107946 & 606 & 0 & 86700 & 648 & 0 & 95935,8 & 600 & 0 \\
\hline $\mathrm{DF}$ & 285,9 & 66 & 0 & 1610 & 47 & 0 & 1466 & 36 & 0 & 1834,3 & 40 & 0 \\
\hline TOTAL & $1.303,404$ & 30.846 & 25 & $1.445,851$ & 29.777 & 45 & $1.660,400$ & 29.899 & 46 & $1.751,862$ & 29.487 & 46 \\
\hline
\end{tabular}

Fonte: Elaborada a partir dos dados do Anuário Estatístico do Brasil - IBGE dos anos de 1976, 1986, 1996 e 2006.
(a) Extensão da rede rodoviária brasileira (em quilômetros), por unidade da federação.
(b) Extensão da rede ferroviária brasileira (em quilômetros), por unidade da federação.
(c) Número de portos brasileiros, por unidade da federação.

Em 1995 o Brasil contava com uma malha rodoviária de mais 1,660 milhão de quilômetros, um crescimento de $14,84 \%$ em relação a 1985 . O modal ferroviário atingiu, no mesmo ano, mais de 29,899 mil quilômetros, apresentando pequena alteração em relação a 1985. Quanto ao sistema portuário, obteve o incremento de um único porto em 10 anos (Tabela 3).

A infra-estrutura no ano de 2005 se apresentou pouco alterada em relação a 1995. O setor rodoviário teve uma expansão de 5,51\% em sua malha $(91.462 \mathrm{~km})$, e o ferroviário, uma redução de $1,38 \%(29,487 \mathrm{~km})$, quando comparados a 1995 . O sistema portuário não apresentou alterações entre os anos 1995 e 2005.

A expansão da infra-estrutura de transporte, entre 1975 e 2005, representada pelas malhas rodoviária, ferroviária e hidroviária em operação, está apresentada na Figura 2. Com relação ao sistema rodoviário, cabe destacar, que este contempla 
somente as estradas federais e estaduais de ligação asfaltadas. Além disso, embora existam projetos de expansão para todos os modais apresentados, e alguns já em fase de implantação, os mesmos não foram contemplados nesta figura.

Em comparação com outros países, o Brasil ocupa a $4^{\mathrm{a}}$ posição em extensão de malha rodoviária, sendo que os Estados Unidos dispõem da maior malha, com 6,4 milhões de quilômetros (USDA, 2007). Em
2005, a malha rodoviária brasileira possuía mais de 1,7 milhão de quilômetros, sendo 1,3 milhão de quilômetros de rodovias municipais, 276,775 mil quilômetros de rodovias estaduais e 93,065 mil quilômetros de rodovias federais. Entretanto, das suas rodovias, apenas $11,19 \%$ são pavimentadas, e destas $19,7 \%$ se encontram em ótima/boa situação, $34,7 \%$ apresentam deficiências e $45,6 \%$ são ruins/ péssimas (Tabela 4).
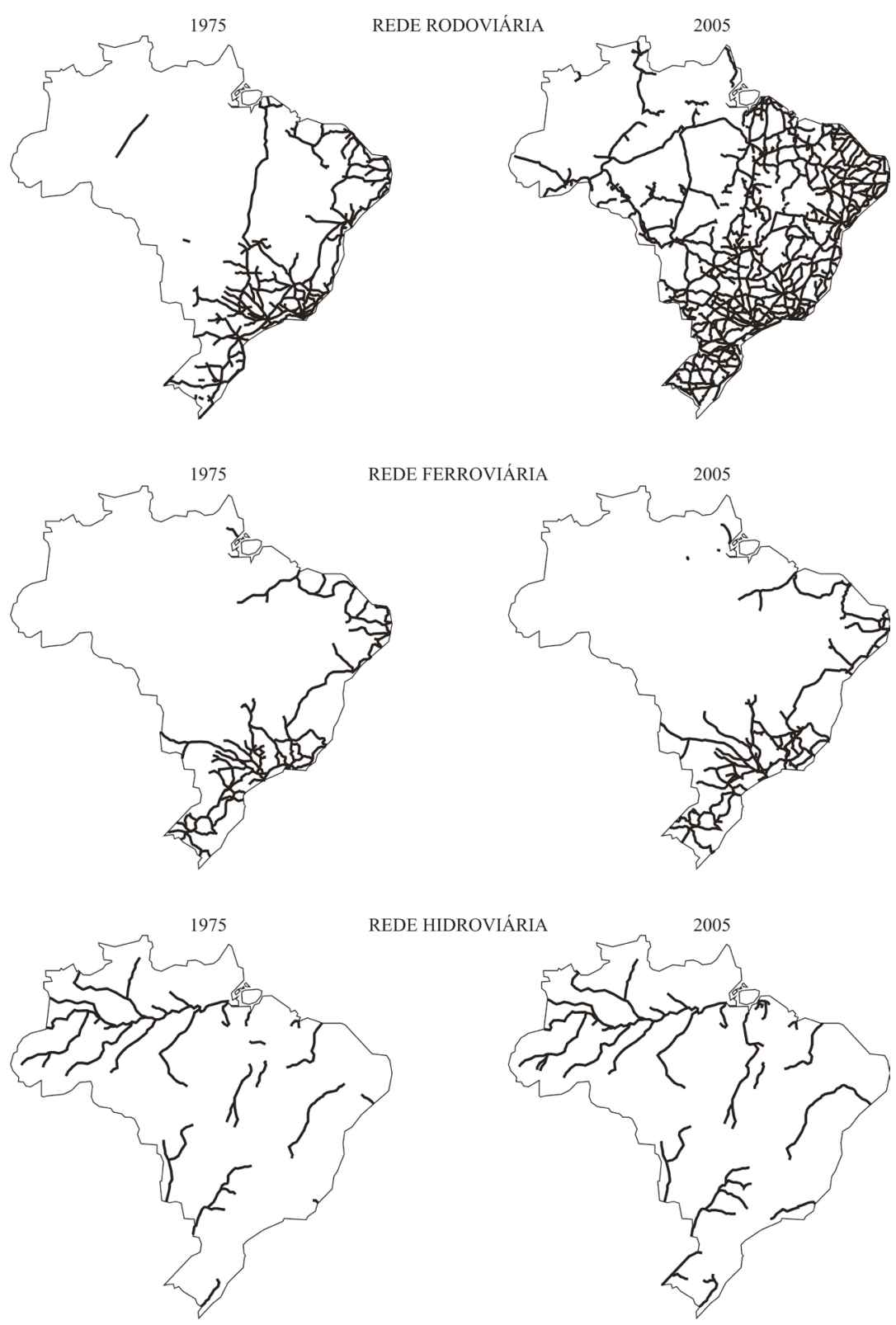

Figura 2. Malhas rodoviária, ferroviária e hidroviária dos anos de 1975 e 2005.

Fonte: Elaborada a partir dos dados do Atlas Nacional do Brasil (IBGE, 2006a). 
Tabela 4. Extensão da malha rodoviária no ano de 2005 (em quilômetros).

\begin{tabular}{lccc}
\hline JURISDIÇÃO & PAVIMENTADA & NÃO PAVIMENTADA & TOTAL \\
\hline Rodovias federais & $59.933,1$ & $35.131,9$ & 93.065 \\
Rodovias estaduais & 115,426 & $161.349,9$ & $276.775,9$ \\
Rodovias municipais & $22.734,8$ & $1.359 .286,3$ & $1.382 .021,1$ \\
TOTAL & $196.093,9$ & 1.413 .982 & 1.751 .862 \\
\hline
\end{tabular}

Fonte: Elaborada a partir dos dados da Agência Nacional de Transportes Terrestres - ANTT, 2006.

No Brasil, 61,1\% do transporte de carga é feito por rodovias, mesmo sendo este o sistema mais oneroso. Problemas de manutenção das rodovias, caminhões que trafegam com excesso de carga em sistemas viários com fiscalização deficiente geram ainda maiores custos de transporte. Por isso, o trajeto percorrido pela soja, da área de produção ao armazém e, desses, para a fábrica ou porto, ou ainda, diretamente da área de produção para a fábrica ou porto, deveria contar com a participação efetiva dos segmentos ferroviário e hidroviário, para redução dos dispêndios (SOARES; CAIXETAFILHO, 1997). Conforme Galvão (1996), essa predominância do modal rodoviário pode ser explicada pelas dificuldades que outras categorias de transporte enfrentam para atender eficientemente aos aumentos de demanda em áreas mais afastadas do país, as quais não são servidas por ferrovias ou hidrovias.

A malha ferroviária brasileira possui uma extensão de 29.487 quilômetros, sendo que 28.112 quilômetros estão distribuídos entre sete concessionárias (CONFEDERAÇÃO NACIONAL DE TRANSPORTES, 2006), que no ano de 2006 investiram aproximadamente 2,4 bilhões de reais (ANTT, 2006). A frota ferroviária possui 83.700 vagões, 3.100 carros e 2.500 locomotivas. Essa estrutura deixa o Brasil na $10^{\mathrm{a}}$ posição no ranking de países com maior malha ferroviária, que tem os Estados Unidos na liderança com 227.736 quilômetros (USDA, 2007). A soja representou $7,9 \%$ do total das cargas transportadas pelo sistema ferroviário, que movimentou aproximadamente 29 milhões de toneladas (ANTT, 2006).
Além da extensão da malha ferroviária brasileira ser insuficiente para atender à demanda, um dos grandes gargalos do segmento são as passagens de nível no contorno dos centros urbanos, bem como as invasões na faixa de domínio das ferrovias. Segundo a ANTT (2006), 824 trechos estão comprometidos por famílias que moram em casas construídas muito próximas aos trilhos. Para evitar os acidentes nessas áreas urbanas, a velocidade média dos trens cai de 40 para 5 quilômetros por hora, reduzindo a eficiência operacional, além das diferenças de bitolas, que reduzem a extensão total da malha. Outro problema no modal ferroviário é o uso de vagões inadequados, além da pequena oferta de material rodante e a baixa qualidade do já existente, que se confirmam como deficiências da infra-estrutura.

Já, os números do segmento hidroviário brasileiro revelam uma malha de 42.000 quilômetros, dos quais apenas $23,8 \%$ estão sendo utilizados, cerca de 10.000 quilômetros (ANTAQ, 2006). Este sistema é pouco utilizado para o escoamento da soja em grãos, para a exportação, devido à falta de investimentos públicos e de interesse do setor privado, e diferentemente dos Estados Unidos, devido à existência de poucos rios navegáveis que desembocam no oceano, com exceção do sistema Tietê-Paraná.

Para integrar o sistema hidroviário às demais formas de transportes são necessários estudos rigorosos sobre a navegação fluvial e seu real papel na degradação do meio ambiente. Sua efetivação e viabilização demandam um processo de incentivo à utilização, que, entre outras medidas, preveja a localização adequada e a operacionalização de terminais hidroviários.

Quanto aos portos marítimos, fica a expectativa 
de medidas que reforcem a sua modernização e estimulem o aumento de sua capacidade e eficiência, passando, inclusive, pela expansão de atividades voltadas à movimentação por cabotagem. Vale ressaltar que um conjunto de ações, como a redução dos custos dos serviços de apoio portuário (praticagem) e a reestruturação dos órgãos de fiscalização do governo nos portos, tendo em vista uma maior agilidade na operacionalização do trânsito aduaneiro, para aproximar o nível de eficiência dos portos brasileiros aos padrões internacionais, precisam ser implementadas.

De qualquer forma, o principal entrave à modernização é de natureza estrutural-gerencial, devendo os portos ser entendidos não mais de forma isolada, mas como integrantes de complexos logísticos. A instalação de novos terminais intermodais e a construção e finalização de obras complementares ao longo das hidrovias brasileiras, também num horizonte de médio e longo prazo, são aguardadas como alternativas estimuladoras para incrementar a viabilidade do transporte hidroviário.

Em vista a este contexto, Castro (2000) afirma que as infra-estruturas ferroviária e hidroviária do país são insuficientes para realizar o transporte de grãos. Isso faz com que, embora mais oneroso, seja necessária a utilização do modal rodoviário para o transporte de grande parte da produção de soja brasileira, mesmo quando se trata de longas distâncias.

O fato de não se utilizar o modal de menor expensa ou a não existência de uma conexão eficiente entre os modais (sistema multimodal) representa um custo adicional na comercialização, dificultando a equiparação dos níveis de preços no mercado interno e externo de produtos agrícolas, inclusive a soja (FIGUEIREDO; FLEURY; WANKE, 2003). Por isso, a viabilização e integração multimodal dos transportes (rodoviário, ferroviário e hidroviário) é uma alternativa para aumentar a competitividade desta commodity, integrando áreas de produção, centros consumidores e mercado internacional (MARTINS, 2001).
Lieb (1998) aponta que as diferentes características entre os modais, como custos e outros aspectos qualitativos, podem ser economicamente desejáveis. Entre a origem e o destino de um determinado produto pode-se utilizar mais de uma modalidade de transporte, com as vantagens inerentes de cada uma delas, o que deve resultar num serviço de menor custo e/ou de melhor qualidade. Assim a intermodalidade, além de nortear os investimentos no setor dos transportes, contribui para a redução dos custos, pois, com isso, ocorre uma tendência de se substituir o transporte rodoviário de longa distância por transportes alternativos, aumentando ainda mais a competitividade da soja no mercado internacional.

\section{Considerações finais}

Ao longo de trinta anos, compreendidos entre 1975 e 2005, a infra-estrutura de transporte no Brasil não acompanhou a expansão da cultura da soja. Enquanto os avanços tecnológicos permitiram à cultura da soja um intenso processo de territorialização, com incremento da área plantada de $305 \%$, avançando por todo o território brasileiro, abrangendo 1955 municípios produtores, a infraestrutura de transporte apresentou um crescimento modesto $25,3 \%$. O modal rodoviário cresceu $34,4 \%$, o ferroviário apresentou uma redução de $4,4 \%$ e o número de portos cresceu 45,75\%.

Assim, o modal rodoviário, definido como modelo de integração desde a década de 70, no médio prazo, continuará sendo fundamental para o escoamento da commodity. A redução dos custos de transporte no curto prazo e a modernização do setor rodoviário devem ser estimuladas por meio de providências que favoreçam o seu incremento tecnológico.

Além disso, é de fundamental importância que os setores ferroviário e hidroviário recebam investimentos, tanto da iniciativa pública quanto da privada, para minimizar os custos de produção, consolidando sua importância no sistema de 
escoamento da soja, de integração do país e de desenvolvimento regional, tornando a economia brasileira mais competitiva.

\section{Agradecimentos}

Agradecemos a Senhora Yara Araújo Siqueira Ceccatto, da unidade do IBGE de Curitiba, e aos Professores Osvaldo Coelho Pereira Neto e Rosely Sampaio Archela, do Departamento de Geociências da UEL.

\section{Referências}

AGÊNCIA NACIONAL DE TRANSPORTES AQUAVIÁRIOS - ANTAQ. Estatísticas. 2006. Disponível em: <http://www.antaq.gov.br>. Acesso em: 12 jan. 2007.

AGÊNCIA NACIONAL DE TRANSPORTES TERRESTRES - ANTT. Condições das Rodovias. 2006. Disponível em: $<$ http://www.antt.gov.br $>$. Acesso em: 10 jan. 2007.

CASTRO, N. R. Os desafios da regulação do setor de transporte no Brasil. Revista de Administração Pública, Rio de Janeiro, v. 34, n. 5, p. 119-142, 2000.

Infra-estrutura de transporte e expansão da agropecuária brasileira. Planejamento e Políticas Públicas, Brasília, v. 25, n. 1, p. 105-138, 2002.

Formação de preços no transporte de carga. Pesquisa e Planejamento Econômico, Brasília, v. 33, n. 1, p. 331-350, 2003.

CÂMARA, G. M. S. A Cultura da Soja. Piracicaba: ESALQ/USP, 1996.

COMPANHIA NACIONAL DE ABASTECIMENTO - CONAB. Safras. 2006. Disponível em: <http://www. conab.gov.br>. Acesso em: 8 jan. 2007.

CONFEDERAÇÃO NACIONAL DA AGRICULTURA E PECUÁRIA - CNA. Indicadores rurais. 2006. Disponível em: <http://www.cna.org.br>. Acesso em: 6 mar. 2007.

CONFEDERAÇÃO NACIONAL DE TRANSPORTES - CNT. Pesquisa Ferroviária CNT. 2006. Disponível em: $<$ http://www.cnt.org.br>. Acesso em: 11 mar. 2007.

FIGUEIREDO, K. F.; FLEURY, P. F.; WANKE, P. Logística e gerenciamento da cadeia de suprimentos: planejamento do fluxo de produtos e dos recursos. São Paulo: Atlas, 2003.
FOOD AND AGRICULTURE ORGANIZATION OF THE UNITED NATIONS - FAO. Trade indices. 2006. Disponível em: <http://faostat.fao.org>. Acesso em: 16 mar. 2007.

GALVÃO, O. J. A. Desenvolvimento dos transportes e integração regional no Brasil: uma perspectiva histórica. Planejamento e Políticas Públicas, Brasília, n. 13, p. 183-211, 1996.

GIL, A. C. Técnicas de pesquisa em economia e elaboração de monografias. São Paulo: Atlas, 2002.

HESSE, M; RODRIGUE, J. P. The transport geography of logistic and freight distribution. Journal of Transport Geography, London, v. 12, n. 3, p. 171-184, 2004.

IBGE. Censo agropecuário: 1970. Rio de Janeiro: IBGE, 1970.

. Anuário Estatístico do Brasil: 1976. Rio de Janeiro: IBGE, 1977. $38 \mathrm{v}$.

. Anuário Estatístico do Brasil: 1986. Rio de Janeiro: IBGE, 1987. $47 \mathrm{v}$.

Anuário Estatístico do Brasil: 1996. Rio de Janeiro: IBGE, 1997a. $56 \mathrm{v}$.

Anuário Estatístico do Brasil: 2006. Rio de Janeiro: IBGE, 2007a. $65 \mathrm{v}$.

$2006 \mathrm{a}$.

. Atlas Nacional do Brasil. Rio de Janeiro: IBGE,

Pesquisa agrícola municipal: 1995. Disponível em: $<$ http://www.sidra.ibge.gov.br>. Acesso em: 2 maio $2007 b$.

Produção agrícola municipal 1975-1994. Rio de Janeiro: IBGE, $1997 \mathrm{~b}$.

. Produção agrícola municipal 2005: cereais, leguminosas e oleaginosas. Rio de Janeiro: IBGE, $2006 \mathrm{~b}$.

INSTITUTO BRASILEIRO DE ECONOMIA - IBRE. Logística, o calcanhar-de-aquiles do agronegócio. Conjuntura econômica, Rio de Janeiro, v. 59, n. 5, p. 7-8, 2005.

LIEB, R. C. What's the future for third-party logistics? Supply Chain Management Review, New York, v. 2, n. 1, p. 71-79, 1998.

MARTINS, R. S. Prognósticos da demanda por transportes para grãos e estrangulamentos na infraestrutura no Estado do Paraná. Revista de Economia e Sociologia Rural, Brasília, v. 39, n. 2, p. 51-80, 2001.

MARTINS, R. S.; REBECHI, D.; PRATI, C. A.; CONTE, H. Decisões estratégicas na logística do agronegócio: compensação de custos transporte-armazenagem para 
a soja no Estado do Paraná. Revista de Administração Contemporânea, Curitiba, v. 9, n. 1, p. 53-78, 2005.

OJIMA, A. L. R. O. Perfil da logística de transporte de soja no Brasil. Informações Econômicas, São Paulo, v. 36, n. 1, p. 17-25, 2006.

REID, J.; SOUZA JUNIOR, W. C. Infrastructure and conservation policy in Brazil. Conservation Biology, Boston, v. 19, n. 3, p. 740-746, 2005.

ROEHNER, B. M. The role of transportation costs in the economics of commodity markets. American Journal of Agricultural Economics, St. Paul, v. 78, n. 2, p. 339-353, 1996.

SAMUELS, D. A economia política da reforma macroeconômica no Brasil, 1995-2002. Dados, Rio de Janeiro, v. 46, n. 4, p. 805-835, 2003.

SHORT, J.; KOPP, A. Transport infrastructure: investment and planning (policy and research aspects). Transport Policy, The Hague, v. 12, n. 4, p. 360-367, 2005.
SOARES, M. G.; CAIXETA-FILHO, J. V. Caracterização do mercado de fretes rodoviários para produtos agrícolas. Gestão \& Produção, São Carlos, v. 4, n. 2, p. 186-203, 1997.

TOYOSHIMA, S.; FERREIRA, M. J. Encadeamentos do setor de transportes na economia brasileira. Planejamento e Políticas Públicas, Brasília, v. 1, n. 25, p.139-166, 2002.

UNITED STATES DEPARTMENT OF AGRICULTURE - USDA. Oilseeds: world markets and trade. 2006. Disponível em: <http://www.usda.gov>. Acesso em: 16 mar. 2007.

ZARZOSO; I. M.; BURGUET, C. S.; MENÉNDEZ, L. G. The impact of transport costs on international trade: the case of spanish ceramic exports. Maritime Economics \& Logistics, Hampshire, v. 5, n. 2, p. 179-198, 2003. 
